\title{
CORRELATION BETWEEN BODY MASS INDEX AND MICROALBUMINURIA IN ESSENTIAL HYPERTENSIVE ADULTS
}

\author{
IRENGBAM SUSUPRIYA DEVI ${ }^{1}$, GLADYS RAI ${ }^{1 *}$, V. P. S PUNIA ${ }^{2}$, MANOJ KUMAR NANDKEOLIAR ${ }^{1}$
}

\begin{abstract}
${ }^{1}$ Department of Biochemistry, School of Medical Sciences and Research, Sharda University, Greater Noida, Uttar Pradesh, India, ${ }^{2}$ Department of Medicine, School of Medical Sciences and Research, Sharda University, Greater Noida, Uttar Pradesh, India. Email: rai.gladys@gmail.com
\end{abstract}

Received: 18 January 2020, Revised and Accepted: 06 March 2020

\begin{abstract}
Objective: This study aimed to find the correlation between body mass index (BMI) and microalbuminuria (MA) in essential hypertensive adults.

Methods: This study included 35 essential hypertensive patients in the 18-65 years of age group, who satisfied the inclusion criteria. Arterial blood pressure was measured by a sphygmomanometer and the first voided early morning urine sample was collected for the estimation of microalbumin.

Results: The mean age of the population studied was $49 \pm 11.08$ in essential hypertensive patients and $46.89 \pm 11.10$ in the control group. The mean value of BMI in the hypertensive group was found to be $27.59 \pm 5.45$. In the present study, the mean value of microalbumin in essential hypertensive patients was $20.95 \pm 16.96$. A significant positive correlation between BMI and MA was observed in the study with $p<0.001$.
\end{abstract}

Conclusion: Our study shows a positive correlation between BMI and MA. Therefore, this study will help in the early detection of renal injury and prevents its progression to renal failure by lifestyle and diet modifications.

Keywords: Body mass index, Essential hypertension, Microalbuminuria

(C) 2020 The Authors. Published by Innovare Academic Sciences Pvt Ltd. This is an open access article under the CC BY license (http://creativecommons. org/licenses/by/4. 0/) DOI: http://dx.doi.org/10.22159/ajpcr.2020.v13i5.37075

\section{INTRODUCTION}

About 1 billion people are suffering from hypertension worldwide [1] and $12.8 \%$ of annual deaths are due to hypertension [2]. In India, the incidence in adults is around $10 \%$ [3], affecting $33 \%$ and $25 \%$ of the rural and urban populations, respectively [4]. Around 5-15\% of essential hypertensive patients present with proteinuria and develop renal diseases. Hypertension is also a major cause of heart failure, coronary artery disease, and peripheral arterial disease [3].

The classic obesity parameters are body mass index (BMI), waist-tohip ratio, and waist circumference [5]. Other environmental factors such as socioeconomic status, ethnicity, the region of residence, season, and urban living are related to obesity. The effect of obesity is seen majorly in the heart, liver, kidney, lungs, colon, skin, vessels, and brain [6]. Overweight and obesity are associated with hypertension and atherosclerotic cardiovascular disease or diabetes [7]. There have been several studies on the relationship between overweight/obesity and hypertension. Obese people are at 5 times higher risk of hypertension than people of normal weight. An increase in blood pressure is either stimulated through activation of the sympathetic nervous system or through increased sodium retention by the kidneys [8]. BMI is associated with microalbuminuria (MA) and albumin-creatinine ratio independently in hypertensive patients. Obesity leads to increased glomerular hyper-filtration and hypertrophy. An increase in the systemic pressure in the glomerular transmission enhances the glomerular capillary's susceptibility to barotraumas which in turn increases the risk of glomerular hypertensive injury [9].

MA is a condition in which the urinary albumin excretion (UAE) is 30-300 mg/24 h [3] (20-200 mg/l) [7] or albumin/creatinine ratio of $30-300 \mathrm{mg} / \mathrm{g} 3$. Numerous studies have shown that MA is independently associated with atherosclerosis and ischemic heart disease and has also been found in a large number of essential hypertensive patients [3]. This increase in the presence of albumin in the urine in essential hypertensive patients may be due to the damage in the glomerular capillaries [9]. MA is used as a predictive marker for cardiovascular risk and mortality [10]. It is also used as an early marker for intra-renal vascular dysfunction among the essential hypertensive patients [11]. Comparing to individuals with normoalbuminuria, patients with MA have a higher chance of developing stroke in the future [3]. However, the mechanism that leads to MA in hypertensive patients is still not fully understood or proven [10]. Therefore, the present study was undertaken to assess MA in essential hypertensive adults and find the relationship, if any, between increased BMI and MA in essential hypertensives.

\section{METHODS}

This study was a cross-sectional study that was conducted in the Department of Medicine, Sharda Hospital and Department of Biochemistry, School of Medical Sciences and Research, Sharda University, Greater Noida. Patients visiting the Department of Medicine, both OPD and IPD, Sharda Hospital, between May 2019 and December 2019 were evaluated. This study included essential hypertensive adults in the age group of 18-65 years with a blood pressure of $>140 / 90 \mathrm{mmHg}$ (as per the guidelines of ACC/AHA 2017). The study sample included 35 essential hypertensive adults and 35 healthy controls. The research excluded patients with secondary hypertension, any symptoms of acute infection, pregnant women, women on birth control pills, patients with diabetes mellitus, renal disorders, cardiovascular diseases, and thyroid diseases.

Height and weight were measured in light clothing and without shoes. The arterial blood pressure was assessed using a sphygmomanometer, after allowing the patient to rest for $5 \mathrm{~min}$. The first voided early morning urine sample was collected and stored at $-20^{\circ} \mathrm{C}$. MA was estimated on the semi-AutoAnalyzer (Star 21 Plus) by Pyrogallol Red Method (Transasia Bio-Medicals Ltd. in technical collaboration with Erba diagnostics). 
Ethics approval

The study was conducted after obtaining written informed consent from the patient and ethical clearance was taken by the Institutional Ethical Committee.

\section{Statistical analysis}

Categorical variables are presented in number and percentage (\%) and continuous variables presented as mean $\pm \mathrm{SD}$. The normality of data was tested by the Kolmogorov-Smirnov test.

Statistical tests applied as follows:

1. Comparison of the mean calculated by t-test.

2. Pearson correlation was used to see the relationship between variables.

$\mathrm{p}<0.05$ was considered as significant at a $95 \%$ confidence level. The statistical analysis was done using the software SPSS version 24.0.

\section{RESULTS}

The mean age of the population studied was $49.34 \pm 11.08$ essential hypertensive patients and $46.89 \pm 11.10$ healthy controls. Table 1 shows the gender distribution between the two groups. The mean levels of both BMI and MA in the two groups are shown in Fig. 1. The mean value of BMI in the hypertensive group was $27.59 \pm 5.45$, which is the BMI range of overweight (25-29.9). However, this is not significant as $p>0.05(p=0.092)$. The microalbumin means level was found to be significant in the present study. The mean value of microalbumin in essential hypertensive patients was $20.95 \pm 16.96$, which is defined as MA. The comparison of the mean value of BMI and MA between the two groups is shown in Table 2 . The p-value given in the last column of Table 2 shows that there is a significant mean difference between the groups in MA. In the present study, there was no significant difference in the age and BMI between the cases and controls. A positive correlation between BMI and MA was observed (Table 3).

\section{DISCUSSION}

In the early stages of essential hypertension, MA and vascular dysfunction are seen [3]. It is among the earliest indications of kidney injury in patients with hypertension [1]. Several studies have proved the association between MA and high levels of blood pressure [12]. Obesity is also an independent microalbuminuric risk factor [13].

The current study was conducted to assess the relationship between essential hypertension, BMI, and MA. This study included 20 males and 15 females hypertensive patients, 15 males and 20 females healthy controls. Papathanasiou G et al. also found that hypertension prevalence in males was higher than in females in 2015 [8]. The prevalence is lower in females before 50 years of age as compared to males. This is due to the estrogen, but the occurrence increases after menopause rapidly [2].

In this study, the mean value of BMI in the hypertensive group was in the BMI range of overweight (25-29.9). According to the studies done by Hitha et al. [1] and Akintude et al. [14], overweight people have higher chances of having hypertension as compared to obese people whereas Papathanasiou et al.'s study found the prevalence to be higher in obese as compared to overweight [8]. These differences may be due to the difference in social status and economic classes of the population studied [14].

Our results show that hypertensive patients are prone to have MA. This finding is similar to the study done by Aggarwal et al. [3], Nwegbu etal. [15], and Khan et al. [16]. Individuals with MA have higher chances of developing renal failure. This could be due to the increased permeability of the renal and diffused endothelial dysfunction. Increased glomerular hydrostatic pressure and increased glomerular basement membrane permeability are some of the mechanisms suggested for greater UAE in essential hypertensive patients [17]. Hence, diagnosing MA at an early stage may help in taking proper precaution and to initiate appropriate management in hypertensive patients [18].
Table 1: Gender distribution between the groups

\begin{tabular}{llllll}
\hline Gender & \multicolumn{2}{l}{ Group } & Total & Pearson Chi-square & p-value \\
\cline { 2 - 4 } & Case & Control & & & \\
\hline Male & 20 & 15 & 35 & 1.429 & 0.232 \\
Female & 15 & 20 & 35 & & \\
Total & 35 & 35 & 70 & & \\
\hline
\end{tabular}

Table 2: Comparison of mean values of BMI and MA between the two groups

\begin{tabular}{lllllll}
\hline Parameters & Group & n & Mean & $\begin{array}{l}\text { Standard } \\
\text { deviation }\end{array}$ & t-value & p-value \\
& & & & & \\
\hline Age & Case & 35 & 49.34 & 11.08 & 0.927 & 0.357 \\
& Control & 35 & 46.89 & 11.10 & & \\
BMI & Case & 35 & 27.59 & 5.45 & 1.711 & 0.092 \\
& Control & 35 & 25.47 & 4.93 & & \\
MA & Case & 35 & 20.95 & 16.96 & 5.617 & $<0.001$ \\
$(20-200 \mathrm{mg} / \mathrm{l})$ & Control & 35 & 4.84 & 0.68 & & \\
\hline
\end{tabular}

*Significant level, if $\mathrm{p}<0.05$.BMI: Body mass index, MA: Microalbuminuria

Table 3: Correlation between BMI and MA in the case group

\begin{tabular}{llll}
\hline Correlations & & \\
\hline & & BMI & MA (20-200 mg/l) \\
\hline BMI & i. Pearson Correlation & 1 & $0.778^{* *}$ \\
& ii. p-value & - & $<0.001$ \\
& iii. N & 35 & 35 \\
MA & i. Pearson Correlation & $0.778^{* *}$ & 1 \\
$(20-200 \mathrm{mg} / \mathrm{l})$ & ii. p-value & $<0.001$ & - \\
& iii. N & 35 & 35 \\
\hline
\end{tabular}

**Correlation is significant at the 0.001 level (two-tailed). BMI: Body mass index, MA: Microalbuminuria

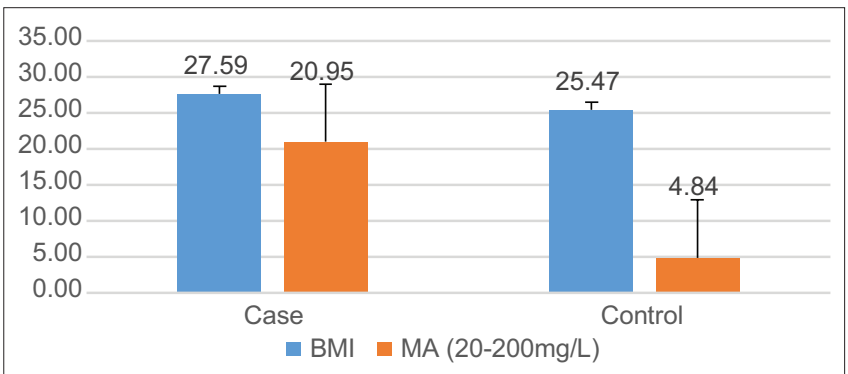

Fig. 1: The mean levels of BMI and MA in the two groups Case: Essential hypertensive adults; Control: Healthy Adults

A positive correlation between BMI and MA was found in the present study, which is in line with the Hitha et al. [1], Poudel et al. [13], and Liu et al.'s report. This relationship between BMI and MA may be due to increased glomerular hyper-filtration and hypertrophy in obesity. An increase in the systemic pressure in the glomerular transmission enhances the susceptibility of the glomerular capillary to barotraumas which in turn increases the risk of hypertensive glomerular injury [9].

\section{CONCLUSION}

Based on our present study and available literature, it can be concluded that there is a positive correlation between BMI and MA in essential hypertensive patients. This study will help in detecting early renal injury in hypertensive patients and with proper treatment progression to renal failure can be prevented. In this study, BMI within the range of 25-29.9 shows a positive correlation with MA. Since BMI, a modifiable factor is associated with MA in essential hypertensive patients, future interventions/lifestyle modifications may be planned for these patients. 


\section{ACKNOWLEDGMENT}

The authors would like to extend heartfelt gratitude to all the teaching, the technical and non-technical staff of the Department of Biochemistry, for the constant encouragement, support, and guidance.

\section{AUTHORS' CONTRIBUTIONS}

Intellectual content, literature search, data analysis, manuscript preparation: Irengbam Susupriya Devi

Manuscript editing and review: Dr. Gladys Rai

Data acquisition: Dr. V.P.S. Punia

\section{CONFLICTS OF INTEREST}

The authors declare that they have no conflicts of interest.

\section{SOURCE OF FUNDING}

The authors declare that there is no source of funding

\section{REFERENCES}

1. Hitha B, Pappachan JM, Pillai HB, Sujathan P, Ramakrishna CD, Jayaprakash $\mathrm{K}$, et al. Microalbuminuria in patients with essential hypertension and its relationship to target organ damage: An Indian experience. Saudi J Kidney Dis Transpl 2008;19:411-9.

2. Nayak SR, Jena I, Mishra PK, Behera S, Ray S. Evaluation of serum nitric oxide in essential hypertension and its correlation with severity of disease. Asian J Pharm Clin Res 2016;9 Suppl 2:179-82.

3. Aggarwal HK, Jain D, Mor S, Yadav RK, Jain P. Prevalence and clinical correlates of microalbuminuria in patients with essential hypertension-a tertiary care center cross sectional study. J Assoc Physicians India 2018;66:30-4.

4. Jhawat V, Gupta S, Agarwal BK, Roy P, Saini V. Prevalence and risk factors of essential hypertension and new onset of diabetes in essential hypertension in rural population of Haryana. Int $\mathrm{J}$ Pharm Pharm Sci 2018;10:142-8.

5. Stepień M, Wlazeł RN, Paradowski M, Banach M, Rysz M, Misztal M, et al. Serum concentrations of adinopectin, leptin, resistin, ghrelin and insulin and their association with obesity indices in obese normo and hypertensive patients-pilot study. Arch Med Sci 2012;8:431-6.

6. Jiang SZ, Lu W, Zong XF, Ruan HY, Liu Y. Obesity and hypertension (review). Exp Ther Med 2016;12:2395-9.

7. Thoenes M, Reil JC, Khan BV, Bramlage P, Volpe M, Kirch W, et al. Abdominal obesity is associated with microalbuminuria and an elevated cardiovascular risk profile in patients with hypertension. Vasc Health Risk Manage 2009;5:577-85

8. Papathanasiou G, Zerva E, Zacharis I, Papandreou M, Papageorgiou E, Tzima $\mathrm{C}$, et al. Association of high blood pressure with body mass index, smoking and physical activity in healthy young adults. Open Cardiovasc Med J 2015;9:5-17.

9. Liu X, Liu Y, Chen Y, Li Y, Shao X, Liang Y, et al. Body mass index (BMI) is associated with microalbuminuria in Chinese hypertensive patients. Int J Environ Res Public Health 2015;12:1998-2008.

10. Li Y, Wan Z, Sun Y, Lu W, Yao W, Yu X, et al. Relationship between serum aldosterone and microalbuminuria in patients with essential hypertension. Int J Clin Exp Pathol 2016;9:10635-42.

11. Roopa AN, Reddy KS, Chandrashekara P, Umabai KR, Madhuvan HS. Study of microalbuminuria and insulin resistance in patients with essential hypertension and metabolic syndrome and its relationship to target organ damage. J Med Sci Health 2015;1:05-9.

12. Sharma DP, Durgeshwar DK, Suruchi DK, Das DR. Prevalence of microalbuminuria in hypertensive patients in Darbhanga medical college Laheriasarai Darbhanga and hospital. IJMBS 2019;3:42-5

13. Poudel B, Yadav BK, Nepal AK, Jha B, Raut KB. Prevalence and association of microalbuminuria in essential hypertensive patients. N Am J Med Sci 2012;4:331-5.

14. Akintunde AA, Akinwusi PO, Adebayo RA, Ogunyemi S, Opadijo OG. Burden of obesity in essential hypertension: Pattern and prevalence. Niger J Clin Pract 2010;13:399-402.

15. Nwegbu MM, Akintan AG, Irabor EO. Prevalence of microalbuminuria in newly diagnosed hypertensives in a tertiary hospital setting, using a semi-quantitative screening tool. Int Res J Basic Clin Stud 2016;4:010-3.

16. Khan I, Dars AG, Shah NA, Shah SZ. Essential hypertension; frequency of microalbuminuria in patients with essential hypertension. Prof Med J 2018;25:854-9.

17. Marudhaiveeran GM, Radhakrishnan S, Alphonse F. Prevalence of microalbuminuria among patients with essential hypertension. Trop J Med Res 2014;17:76-80.

18. Kumar HA, Rekha NH, Raghav ED. A study of microalbuminuria in patients with essential hypertension. Int $\mathrm{J}$ Contemp Med Res 2016;3:1468-70. 